\title{
Cucurbitacin I inhibits STAT3, but enhances STAT1 signaling in human cancer cells in vitro through disrupting actin filaments
}

\author{
Hui GUO ${ }^{1,2}$, Shan KUANG ${ }^{1,2}$, Qiao-ling SONG ${ }^{1,2}$, Man LIU ${ }^{1,2}$, Xiao-xiao SUN ${ }^{1,2}$, Qiang YU ${ }^{1,2}$ \\ ${ }^{1}$ Shanghai Institute of Materia Medica, Chinese Academy of Sciences, Shanghai 201203, China; ${ }^{2}$ University of Chinese Academy of \\ Sciences, Beijing 100049, China
}

\begin{abstract}
STAT1 and STAT3 are two important members of the STAT (signal transducers and activators of transcription) protein family and play opposing roles in regulating cancer cell growth. Suppressing STAT3 and/or enhancing STAT1 signaling are considered to be attractive anticancer strategies. Cucurbitacin I (Cul) isolated from the cucurbitacin family was reported to be an inhibitor of STAT3 signaling and a disruptor of actin cytoskeleton. In this study we investigated the function and mechanisms of Cul in regulating STAT signaling in human cancer cells in vitro. Cul (0.1-10 mmol/L) dose-dependently inhibited the phosphorylation of STAT3, and enhanced the phosphorylation of STAT1 in lung adenocarcinoma A549 cells possibly through disrupting actin filaments. We further demonstrated that actin filaments physically associated with JAK2 and STAT3 in A549 cells and regulated their phosphorylation through two signaling complexes, the IL-6 receptor complex and the focal adhesion complex. Actin filaments also interacted with STAT1 in A549 cells and regulated its dephosphorylation. Taken together, this study reveals the molecular mechanisms of Cul in the regulation of STAT signaling and in a possible inhibition of human cancer cell growth. More importantly, this study uncovers a novel role of actin and actin-associated signaling complexes in regulating STAT signaling.
\end{abstract}

Keywords: cucurbitacin I; cancer cells; STAT1; STAT3; actin; phosphorylation

Acta Pharmacologica Sinica (2018) 39: 425-437; doi: 10.1038/aps.2017.99; published online 9 Nov 2017

\section{Introduction}

The Janus kinase (JAK)/signal transducer and activator of transcription (STAT) signaling pathways mediate the signal transduction of various cytokines and growth factors in the regulation of many physiological processes, such as immune responses, hematopoiesis, and stem cell renewal ${ }^{[1-3]}$. Dysregulation of JAK/STAT signaling often occurs in various diseases, including cancer ${ }^{[4,5]}$. Activating mutations in JAKs and STATs play causal roles in hematologic neoplasms ${ }^{[6-8]}$, as well as in solid tumors, and have prognostic significance ${ }^{[9-13]}$.

STAT3 promotes cell proliferation and survival, and also inhibits apoptosis, by up-regulating the expression of growth stimulatory genes, such as c-Myc, cyclin-D1, Bcl-xl, and survivin; STAT3 also functions as an oncogene in various types of cancers $^{[14,15]}$. Furthermore, it increases the expression of VEGF, twist, and MMP, promoting tumor angiogenesis, epithelial-

\footnotetext{
* $T o$ whom correspondence should be addressed.

E-mail qyu@simm.ac.cn

Received 2017-06-17 Accepted 2017-07-09
}

mesenchymal transition (EMT), and metastasis ${ }^{[16-18]}$. The major cytokine that activates STAT3 is IL- $6^{[19]}$. IL-6 binds to its receptor IL-6Ra in the plasma membrane and forms a hexamer with the signal-transducing protein GP130, which activates the GP130-associated JAKs (JAK1, JAK2 or TYK2, depending on the cell type), followed by JAK-mediated GP130 phosphorylation and STAT3 recruitment and activation ${ }^{[20,21]}$. Therefore, blocking IL-6/JAK/STAT3 signaling has become an attractive strategy for cancer treatment ${ }^{[22]}$.

In contrast to STAT3, STAT1 mediates the anti-tumor activity of IFN- $\gamma$ in tumor cells to promote cell cycle arrest and apoptosis and negatively regulates angiogenesis ${ }^{[1,23-27]}$. IFN- $\gamma$ binds to its receptor IFN- $\gamma R 1 / I F N-\gamma R 2$, resulting in receptor allosteric changes and the transactivation of JAK1 and JAK2 and leading to STAT1 activation ${ }^{[28]}$. STAT1 mainly acts as a tumor suppressor in many tumors. For example, STAT1-deficient mice are more susceptible to chemical carcinogens ${ }^{[29,30]}$. High levels of STAT1 activity correlated with good prognosis in several types of cancers ${ }^{[31-35]}$. Therefore, in contrast to STAT3, enhancing STAT1 activity has also been considered to be an attractive strategy for treating cancer. 
The activities of the STATs are regulated by both kinase phosphorylation and phosphatase dephosphorylation. JAK1 and JAK2 are two major tyrosine kinases involved in STAT1 and STAT3 phosphorylation, respectively. Protein tyrosine phosphatases TCPTP and SHP2 are reported to be responsible for p-STAT1 dephosphorylation, while TCPTP, SHP2, SHP1 and PTPRT are responsible for p-STAT3 dephosphorylation ${ }^{[36]}$.

The actin cytoskeleton plays important roles in a variety of cellular processes, including mechanical support, cytokinesis, cell migration, differentiation, and endocytosis. The actin cytoskeleton exists in different structural forms that have specific functions. Stress fibers are contractile actin bundles that are necessary for cell-cell or cell-ECM adhesion ${ }^{[37]}$. They often anchor to focal adhesions, through which they connect to the extracellular matrix $(\mathrm{ECM})^{[38]}$. Focal adhesions are multi-protein assemblies that transduce mechanical forces and regulatory signals between the ECM and the actin cytoskeleton. Vice versa, the actin cytoskeleton directs focal adhesion assembly and disassembly and organization ${ }^{[39]}$. Actin is also a major component of the cell cortex, a specialized layer of cytoplasmic proteins on the inner face of the plasma membrane, and plays a central role in cell shape control and contractile ring formation during cytokinesis ${ }^{[40]}$. Mounting evidence indicates that the actin cytoskeleton is not only a structural protein but also a key regulator of cellular signaling ${ }^{[41-47]}$.

Cucurbitacin I (CuI) belongs to the cucurbitacin family, which are tetracyclic triterpenoids. CuI was reported to be an inhibitor of STAT3 phosphorylation ${ }^{[48]}$ and a disruptor of the actin cytoskeleton ${ }^{[49-51]}$. It has anti-cancer activity both in vitro and in vivo. However, the molecular mechanisms of its action and the relationships between the two functions have not yet been elucidated.

In this study, we investigated the mechanisms of Cul in the regulation of STAT signaling and actin filaments, particularly the connections between the two. We found that $\mathrm{CuI}$ affected not only STAT3 signaling but also STAT1 signaling, and it had opposing effects on STAT3 and STAT1, inhibiting STAT3 signaling but enhancing STAT1 signaling. Furthermore, we found a connection between the regulation of STAT signaling and actin filaments. The effects of Cul on STAT signaling were the consequence of disrupting the actin cytoskeleton. Our study not only revealed the molecular mechanisms of $\mathrm{CuI}$ but also uncovered novel JAK/STAT signaling complexes and a novel role of actin in their regulation.

\section{Materials and methods Cells and reagents}

All the cell lines used were obtained from the American Type Culture Collection. A549 cells were cultured in RPMI-1640 (Gibco, Thermo Fisher Scientific, Waltham, MA, USA) supplemented with $10 \%(v / v)$ FBS (Gibco, Thermo Fisher Scientific, Waltham, MA, USA), $100 \mu \mathrm{g} / \mathrm{mL}$ ampicillin and $100 \mu \mathrm{g} / \mathrm{mL}$ streptomycin. All cell lines were cultured at $37^{\circ} \mathrm{C}$ in a humidified atmosphere of $95 \%$ air and $5 \% \mathrm{CO}_{2}$.

The sources of chemicals and reagents were as follows: cucurbitacin I (\# C4493; Sigma-Aldrich, Saint Louis, MO,
USA), complete protease inhibitor cocktail (\# P1860; SigmaAldrich, Saint Louis, MO, USA), biotinylated phalloidin (\# P8716; Sigma-Aldrich, Saint Louis, MO, USA), jasplakinolide (\# sc202191A; Santa-Cruz Biotechnology, Dallas, TX, USA), cytochalasin D (\# 250255, Millipore, Billerica, MA, USA); IL-6 (\# 200-02, Peprotech, Rocky Hill, NJ, USA), IFN-ү (\# 300-02, Peprotech, Rocky Hill, NJ, USA), and rhodamine-phalloidin (\# R415, Thermo Fisher Scientific, Waltham, MA, USA).

\section{Western blot analysis}

Western blotting was performed as previously described ${ }^{[52]}$. Immune complexes were detected by enhanced chemiluminescence (\# WBKLS0500, Millipore, Billerica, MA, USA).

The following primary antibodies were used: rabbit antiJAK2 (\# 3230S, Cell Signaling Technology, Danvers, MA, USA), rabbit anti-pY1007/1008 JAK2 (\# 3776S, Cell Signaling Technology, Danvers, MA, USA), rabbit anti-STAT3 (\# 12640, Cell Signaling Technology, Danvers, MA, USA), rabbit anti-pY705 STAT3 (\# 9145S, Cell Signaling Technology, Danvers, MA, USA), rabbit anti-STAT1 (\# 14994S, Cell Signaling Technology, Danvers, MA, USA), rabbit anti-pY701 STAT1 (\# 7649S, Cell Signaling Technology, Danvers, MA, USA), rabbit anti-TYK2 (\# 14193S, Cell Signaling Technology, Danvers, MA, USA), rabbit anti-pY1054/1055 TYK2 (\# 9321S, Cell Signaling Technology, Danvers, MA, USA), rabbit anti-JAK1 (\#3332S, Cell Signaling Technology, Danvers, MA, USA), rabbit antipY1022/1023 JAK1 (\# 3331S, Cell Signaling Technology, Danvers, MA, USA), mouse anti-a-tubulin (\# sc5286, Santa Cruz Biotechnology, Dallas, TX, USA), rabbit anti-IL-6Ra (\# sc13947, Santa Cruz Biotechnology, Dallas, TX, USA), rabbit anti-GP130 (\# sc655, Santa Cruz Biotechnology, Dallas, TX, USA), rabbit anti-SHP2 (\# sc280, Santa Cruz Biotechnology, Dallas, TX, USA), rabbit anti- $\beta$-actin antibody (\# P30002M, Abmart, CA, USA), rabbit anti-vinculin antibody (\# ab73412, Abcam, Cambridge, UK), and mouse anti-TCPTP antibody (\# PH03L, Calbiochem, Merck Millipore, Billerica, MA, USA).

\section{Pull-down of actin filaments}

A549 cells grown in 100-mm dishes to $100 \%$ confluence were washed with ice-cold PBS, then scraped on ice into homogenization buffer $\left(100 \mathrm{mmol} / \mathrm{L} \mathrm{Na}_{2} \mathrm{HPO}_{4}-\mathrm{NaH}_{2} \mathrm{PO}_{4}, \mathrm{pH} 7.2 ; 2\right.$ $\left.\mathrm{mmol} / \mathrm{L} \mathrm{MgCl}_{2}\right)^{[53]}$ containing $0.01 \% \mathrm{NP}-40,1 \mathrm{mmol} / \mathrm{L}$ PMSF, $1 \mathrm{mmol} / \mathrm{L} \mathrm{Na}_{3} \mathrm{VO}_{4}, 1 \mathrm{mmol} / \mathrm{L} \mathrm{NaF}$, and a complete protease inhibitor cocktail, homogenized for 20 strokes with a Dounce homogenizer and centrifuged at $12000 \times g$ and $4{ }^{\circ} \mathrm{C}$ for $10 \mathrm{~min}$. The supernatant was pre-cleared with monomeric avidin agarose beads (\# 20267, Thermo Fisher Scientific, Waltham, MA, USA), prepared according to the manufacturer's instructions. To pull down actin filaments, biotinylated-phalloidin or biotin (negative control) was added to the pre-cleared lysates and incubated with rotation for $2 \mathrm{~h}$ at $4^{\circ} \mathrm{C}$, followed by incubation with monomeric avidin agarose beads for $1 \mathrm{~h}$. The precipitates were washed 5 times with homogenization buffer and eluted with $10 \mathrm{mmol} / \mathrm{L}$ biotin. The elution was mixed with Laemmli $5 \times$ sample buffer and boiled for $5 \mathrm{~min}$, followed by Western blot analyses. 


\section{Immunoprecipitation}

A549 cells grown in $100 \mathrm{~mm}$ dishes to $100 \%$ confluence were harvested on ice with $50 \mathrm{mmol} / \mathrm{L}$ Tris- $\mathrm{HCl}, \mathrm{pH} 7.4 ; 150$ $\mathrm{mmol} / \mathrm{L} \mathrm{NaCl} ; 1 \mathrm{mmol} / \mathrm{L}$ EDTA; $0.5 \% \mathrm{NP}-40 ; 1 \mathrm{mmol} / \mathrm{L}$ PMSF; $1 \mathrm{mmol} / \mathrm{L} \mathrm{Na}_{3} \mathrm{VO}_{4} ; 1 \mathrm{mmol} / \mathrm{L} \mathrm{NaF}$; and a complete protease inhibitor cocktail. The supernatant was pre-cleared with protein A/G-agarose beads (\# sc2003, Santa Cruz Biotechnology, Dallas, TX, USA) for $1 \mathrm{~h}$ with agitation at $4{ }^{\circ} \mathrm{C}$, followed by incubation with primary antibodies and general agitation at $4{ }^{\circ} \mathrm{C}$ overnight and then with protein A/G-magnetic beads (\# B23201, Selleckchem, Houston, TX, USA) for another $3 \mathrm{~h}$. After washing 5 times with the above lysis buffer, the pellets were mixed with Laemmli 2×sample buffer (\# S3401, Sigma-Aldrich, Saint Louis, MO, USA) and boiled for $5 \mathrm{~min}$, then processed for western blotting analyses.

Antibodies used for immunoprecipitation were as follows: rabbit anti-GP130 antibody (\# sc656, Santa Cruz Biotechnology, Dallas, TX, USA) and mouse anti-vinculin antibody (\# V9131, Sigma-Aldrich, Saint Louis, MO, USA).

\section{In vitro kinase and phosphatase assays}

A JAK2 in vitro kinase assay was performed using JAK2 immunoprecipitates. A549 cells were lysed with kinase lysis buffer (50 mmol/L HEPES, pH 7.4; 150 mmol/L NaCl; 0.15\% TritonX-100; $1 \mathrm{mmol} / \mathrm{L}$ PMSF; $1 \mathrm{mmol} / \mathrm{L} \mathrm{Na}_{3} \mathrm{VO}_{4} ; 1 \mathrm{mmol} / \mathrm{L}$ $\mathrm{NaF}$; and a complete protease inhibitor cocktail) following IL-6 stimulation. Cell lysates were immunoprecipitated with goat anti-JAK2 antibody (\# sc34479, Santa Cruz Biotechnology, Saint Louis, MO, USA). The precipitates were washed and resuspended in kinase reaction buffer $(60 \mathrm{mmol} / \mathrm{L}$ HEPES,

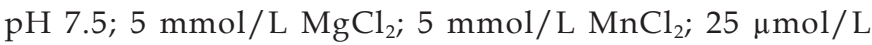
$\mathrm{Na}_{3} \mathrm{VO}_{4}$; and $200 \mu \mathrm{mol} / \mathrm{L}$ ATP) and were then incubated with DMSO, CuI or 2-MS for $15 \mathrm{~min}$ at room temperature, followed by incubation with the biotinylated peptide FLT3 (Cell Signaling Technology, Danvers, MA, USA) for $30 \mathrm{~min}$ at $30^{\circ} \mathrm{C}$; then, the supernatants were transferred to streptavidincoated 96-well plates, incubated for $1 \mathrm{~h}$ at $30^{\circ} \mathrm{C}$, rinsed with $0.1 \%$ PBST (PBS+0.1\% Tween-20) and incubated with the anti-phosphotyrosine antibody 4G10 (\# 05-321MG, Merck Millipore, Billerica, MA, USA) for $2 \mathrm{~h}$ at $37^{\circ} \mathrm{C}$ and with HRPconjugated secondary antibody for $30 \mathrm{~min}$ at $30^{\circ} \mathrm{C}$; after five washes, the TMP substrate (\# 7004S, Cell Signaling Technology, Danvers, MA, USA) was added, and the reaction was stopped by adding $2 \mathrm{~mol} / \mathrm{L} \mathrm{H}_{2} \mathrm{SO}_{4}$; finally, the absorbance was measured at $450 \mathrm{~nm}$.

An in vitro phosphatase assay was performed with SHP2 or TCPTP immunoprecipitates. A549 cells were lysed with PTP lysis buffer (50 mmol/L HEPES, pH 7.2; $150 \mathrm{mmol} / \mathrm{L}$ $\mathrm{NaCl}$; $1 \%$ Triton X-100; $5 \mathrm{mmol} / \mathrm{L}$ EDTA; $1 \mathrm{mmol} / \mathrm{L}$ PMSF; $1 \mathrm{mmol} / \mathrm{L} \mathrm{NaF}$; and a complete protease inhibitor cocktail. Cell lysates were immunoprecipitated with anti-SHP2 (\# sc280, Santa Cruz Biotechnology, Saint Louis, MO, USA) or anti-TCPTP (\# PH03L, Merck Millipore, Billerica, MA, USA) antibodies; the precipitates were washed and re-suspended in PTP reaction buffer (100 mmol/L HEPES, pH 7.0; 150 mmol/L $\mathrm{NaCl}$; and $1 \mathrm{mmol} / \mathrm{L} \mathrm{EDTA}$ ) and then incubated with DMSO,
$\mathrm{CuI}$ or $\mathrm{Na}_{3} \mathrm{VO}_{4}$ for 15 min at room temperature, followed by incubation with the phosphatase substrate 4-nitrophenyl phosphate disodium (\# N4645, Sigma-Aldrich, Saint Louis, $\mathrm{MO}, \mathrm{USA}$ ) for $3 \mathrm{~h}$ at $37^{\circ} \mathrm{C}$. The reaction was terminated with 1 $\mathrm{mol} / \mathrm{L} \mathrm{NaOH}$, and the absorbance was measured at $405 \mathrm{~nm}$.

\section{STAT1 in vitro dephosphorylation assay}

A549 cells receiving different treatments were lysed with hypotonic buffer (10 mmol/L HEPES, pH 7.4; $10 \mathrm{mmol} / \mathrm{L}$ $\mathrm{KCl}$; and $2 \mathrm{mmol} / \mathrm{L} \mathrm{MgCl}_{2}$ ) and nuclear extraction buffer (20 $\mathrm{mmol} / \mathrm{L}$ HEPES, pH 7.4; $1.5 \mathrm{mmol} / \mathrm{L} \mathrm{MgCl}_{2} ; 420 \mathrm{mmol} / \mathrm{L}$ $\mathrm{NaCl}$; and $0.2 \mathrm{mmol} / \mathrm{L}$ EDTA) containing $1 \mathrm{mmol} / \mathrm{L}$ PMSF, 1 $\mathrm{mmol} / \mathrm{L} \mathrm{NaF}$ and a complete protease inhibitor cocktail, followed by centrifugation at $12000 \times g$ and $4^{\circ} \mathrm{C}$ for $10 \mathrm{~min}$. Cell lysates were incubated at $36^{\circ} \mathrm{C}$ for different lengths of time. Laemmli $5 \times$ sample buffer was added to the mixture to facilitate Western blot analyses. For denaturation, lysates from IFN- $\gamma$-stimulated cells were boiled for $5 \mathrm{~min}$ and then cooled on ice.

\section{Immunochemical staining and immunofluorescence analysis}

Cells were plated on coverslips one day before use. After fixation with $4 \%$ formaldehyde for $15 \mathrm{~min}$ at room temperature, cells were permeabilized with $0.05 \%$ Triton X-100 in PBS for 5 min and rinsed with PBS 3 times, followed by blocking with $10 \%$ horse serum in $0.1 \%$ PBST (Tween-20) for $30 \mathrm{~min}$ at $37^{\circ} \mathrm{C}$ and incubation with primary antibodies at $4{ }^{\circ} \mathrm{C}$ overnight and AlexaFluor 488- or AlexaFluor 594-conjugated secondary antibodies at $37^{\circ} \mathrm{C}$ for $1.5 \mathrm{~h}$. For actin staining, rhodaminephalloidin was added and incubated for $1 \mathrm{~h}$ at room temperature. Nuclei were stained with DAPI, which was added for 5 min before washing and mounting with mounting medium (DAKO, Agilent, Santa Clara, CA, USA).

Images were captured at room temperature with a laserscanning confocal microscope FLUOVIEW FV1000 (Olympus, PA, USA) and FV10-ASW software (Olympus, PA, USA). The microscope was equipped with a $60 \times(1.42 \mathrm{NA})$ PLAPON oil objective lens (Olympus, PA, USA). Tagged image file format images were processed using Photoshop software.

Antibodies used were as follows: rabbit anti-JAK2 (\#3230S, Cell Signaling Technology, Danvers, MA, USA), rabbit antipY1007/1008 JAK2 (\#3776S, Cell Signaling Technology, Danvers, MA, USA), rabbit anti-STAT3 (\#12640, Cell Signaling Technology, Danvers, MA, USA), mouse anti-pY705 STAT3, rabbit anti-STAT1, rabbit anti-pY701 STAT1 (Cell Signaling Technology, Danvers, MA, USA), rabbit anti-GP130 antibody (\# sc656, Santa Cruz Biotechnology, Saint Louis, MO, USA), mouse anti-Vinculin antibody (\# V9131, Sigma Aldrich, Saint Louis, MO, USA), rabbit anti-vinculin antibody (\# ab73412, Abcam, Cambridge, UK), secondary AlexaFluor 488-conjugated goat anti-rabbit antibody (\#A11008, Thermo Fisher Scientific, Waltham, MA, USA), secondary AlexaFluor 488-conjugated goat anti-mouse antibody (\#A28175, Thermo Fisher Scientific, Waltham, MA, USA), and secondary AlexaFluor 594-conjugated goat anti-mouse antibody (\#GAM5942, Multi Science Biotech, Hangzhou, China). 


\section{Results}

Cucurbitacin I inhibited STAT3 phosphorylation but enhanced STAT1 phosphorylation

CuI was reported to inhibit STAT3 signaling and to induce apoptosis in cancer cells ${ }^{[48]}$. To confirm and to evaluate the specificity of CuI in STAT signaling, we analyzed the effects of CuI on the phosphorylation of STAT1, which also plays an important but opposing role in the regulation of cancer cell growth. We also found that in contrast to the inhibition of the Y705 phosphorylation of STAT3, CuI increased the Y701 phosphorylation of STAT1 in all the cancer cell lines tested (Figure 1), suggesting that CuI may have opposite effects on STAT1 and STAT3 signaling.
Cucurbitacin I inhibited the phosphorylation of STAT3 but the dephosphorylation of p-STAT1

The phosphorylation status of a protein is a balanced result of kinase phosphorylation and phosphatase dephosphorylation. To clarify whether it was through the modulation of kinase phosphorylation or phosphatase dephosphorylation that CuI exerted its effects on the two STATs, we stimulated lung adenocarcinoma A549 cells with IFN- $\gamma$ or IL-6 to activate STAT1 or STAT3, respectively, following CuI treatment and observed the effects of $\mathrm{CuI}$ on the cytokine-induced phosphorylation of the two STATs. Cul blocked IL-6-induced STAT3 phosphorylation (Figure 2A) but had little effect on IFN- $\gamma$ induced STAT1 phosphorylation (Figure 2B), suggesting that
A
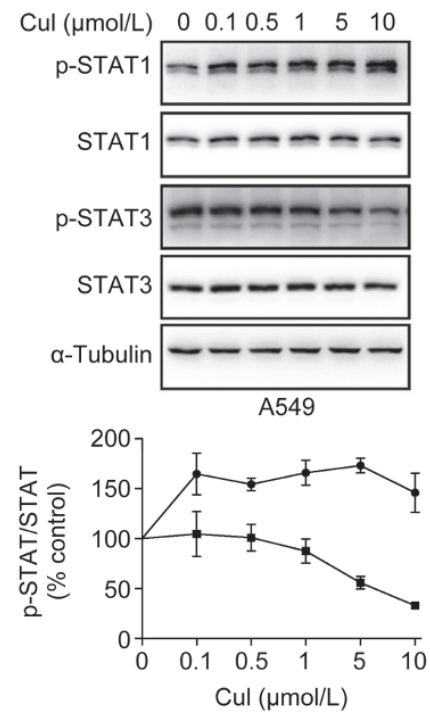

D
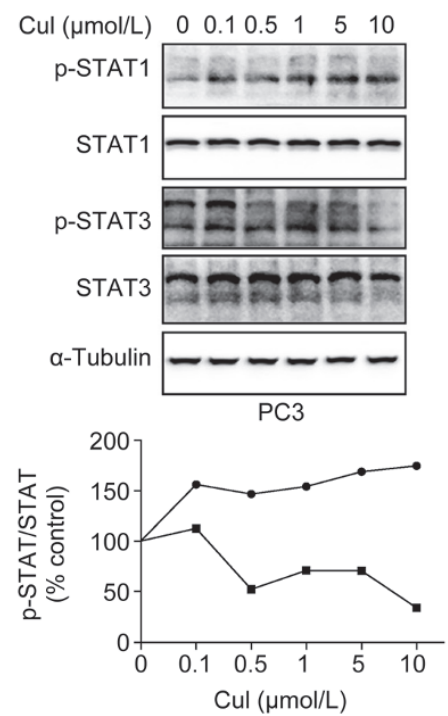

B
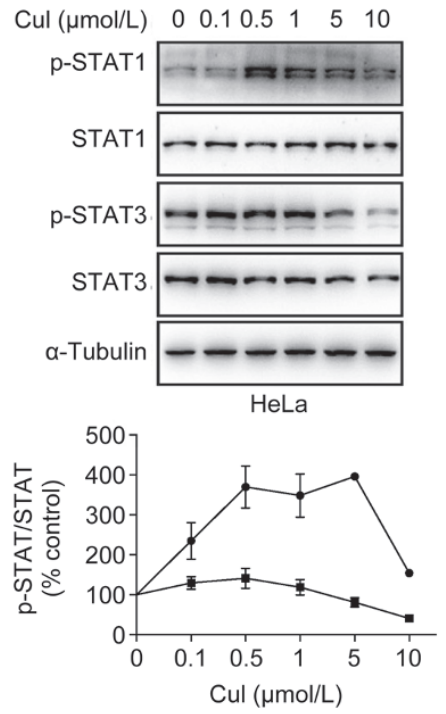

E

Cul $(\mu \mathrm{mol} / \mathrm{L}) \quad \begin{array}{llllll}0 & 0.1 & 0.5 & 1 & 5 & 10\end{array}$
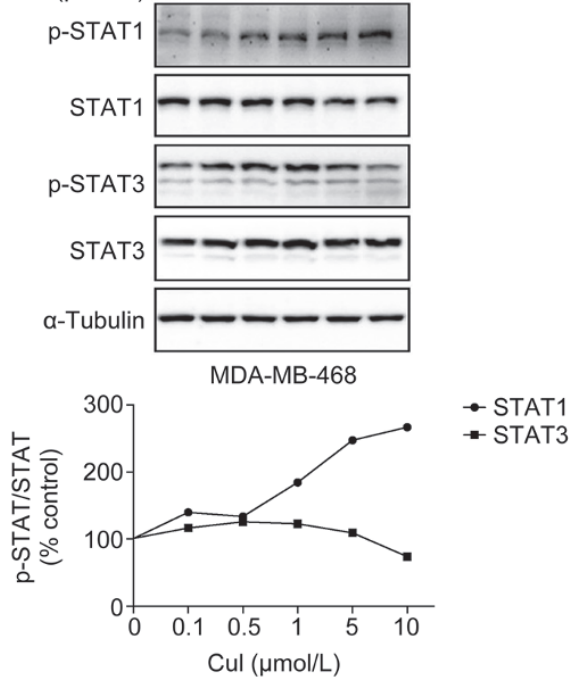

C
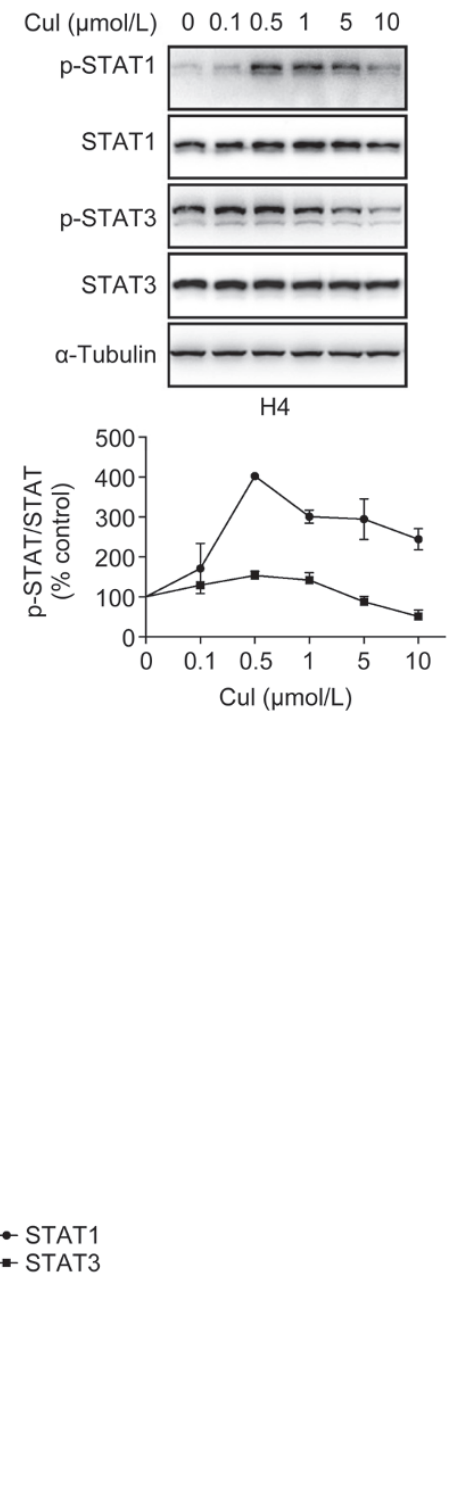

Figure 1. Cucurbitacin I inhibited STAT3 phosphorylation but enhanced STAT1 phosphorylation. Lung adenocarcinoma cell line A549 (A), cervical adenocarcinoma cell line Hela (B), neuroglioma cell line H4 (C), prostate cancer cell line PC3 (D) and mammary adenocarcinoma MDA-MB-468 (E) were treated with Cul for $2 \mathrm{~h}$, and whole cell lysates were processed for Western blot analyses with indicated antibodies. The levels of pY705-STAT3 and pY701-STAT1 in Cul treatments were normalized by $\alpha$-tubulin and quantified to DMSO treatment, and were graphed below the corresponding blots. 
A

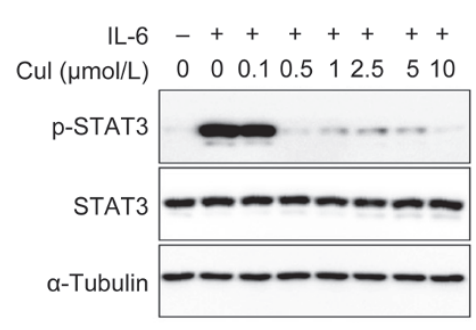

B

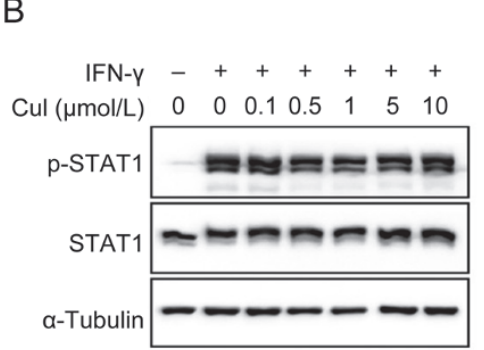

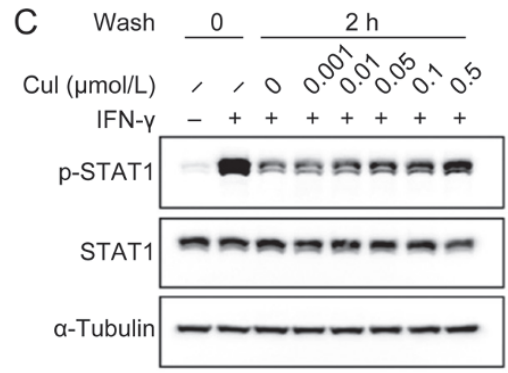
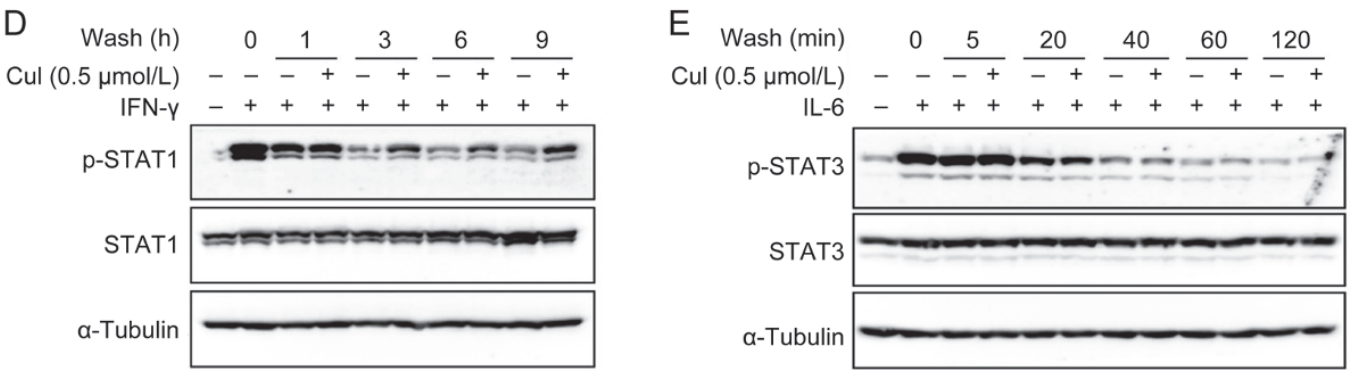

Figure 2. Cucurbitacin I inhibited phosphorylation of STAT3 but dephosphorylation of p-STAT1. (A and B) A549 cells were treated with Cul at indicated concentrations for $2 \mathrm{~h}$, followed by IL-6 (10 ng/mL, A) or IFN-y (10 ng/mL, B) stimulation for $15 \mathrm{~min}$. (C-E) Following IFN-y (C and D) or IL-6 (E) stimulation for $30 \mathrm{~min}$, A549 cells were washed with fresh medium for 3 times and then incubated with or without Cul at indicated concentrations (C) or for indicated time periods ( $\mathrm{D}$ and $\mathrm{E}$ ). Whole cell lysates were processed for Western blot analyses and probed with indicated antibodies.

Cul affected the kinase phosphorylation process of STAT3 but not that of STAT1.

To examine the effects of Cul on the dephosphorylation of p-STAT1 and p-STAT3, we pulse-stimulated A549 cells with IFN- $\gamma$ or IL- 6 and then washed off the cytokines and incubated the cells in the presence or absence of $\mathrm{CuI}$ for different time periods. Cul inhibited the dephosphorylation of p-STAT1 (Figure 2C and D) but had no effect on the dephosphorylation of p-STAT3 (Figure 2E). The concentration of CuI required to inhibit p-STAT1 dephosphorylation appeared to be lower than that required to inhibit STAT3 phosphorylation (Figure 2C). Thus, CuI distinctively regulated STAT3 and STAT1 phosphorylation. It inhibited the phosphorylation of STAT3 but the dephosphorylation of p-STAT1.

Cucurbitacin I did not directly inhibit STAT kinases or phosphatases Because CuI inhibited IL-6-stimulated STAT3 phosphorylation, we examined whether it suppressed the upstream kinases of STAT3 in the IL-6 signaling pathway. JAK2 was reported to be the major kinase involved in IL-6-stimulated STAT3 signaling in the A549 cells $^{[54]}$. However, we observed that JAK2 was constitutively phosphorylated in A549 cells and that IL-6-induced JAK2 phosphorylation could hardly be detected when the cells were cultured in adherent conditions. IL-6-induced JAK2 phosphorylation could be observed only when the cells were cultured in suspension. Therefore, we used suspended cells to examine the effects of CuI on the IL-6-induced phosphorylation of JAK2. We confirmed that IL-6 specifically activated JAK2 but not JAK1 and TYK2 in the A549 cells (Figure $3 \mathrm{~A})$ and found that $\mathrm{CuI}$ inhibited IL-6-induced and constitutive JAK2 phosphorylation in A549 cells (Figure 3B and C).

We next examined whether $\mathrm{CuI}$ directly inhibited JAK2 kinase activity using in vitro kinase assays. We found that $\mathrm{CuI}$ did not inhibit JAK2 kinase activity (Figure 3D), suggesting that $\mathrm{CuI}$ inhibited JAK2 through an indirect mechanism.

Two tyrosine phosphatases, TCPTP and SHP2, were reported to be responsible for p-STAT1 dephosphorylation ${ }^{[55,56]}$. We thus examined whether $\mathrm{CuI}$ inhibited these two phosphatases using an in vitro phosphatase assay. We found that $\mathrm{CuI}$ did not directly inhibit TCPTP or SHP2 activity (Figure 3E). We also lysed cells after IFN-y stimulation and incubated the cell lysates in vitro in the presence or absence of CuI; we found that CuI did not inhibit p-STAT1 dephosphorylation in vitro (Figure 3F), also suggesting that CuI did not directly inhibit p-STAT1 phosphatases.

Disrupting the actin cytoskeleton inhibited STAT3 phosphorylation and p-STAT1 dephosphorylation

$\mathrm{CuI}$ was reported to covalently bind and disrupt the actin cytoskeleton ${ }^{[50]}$. To determine whether the disruption of the actin cytoskeleton could affect STAT signaling, we examined the effects of two known actin-disrupting agents, cytochalasin D (CytoD) and jasplakinolide (Jasp), on the phosphorylation of STAT3 and STAT1. Both CytoD and Jasp blocked the IL6-stimulated phosphorylation of JAK2 and STAT3 (Figure 4A and B) while inhibiting the dephosphorylation of p-STAT1 (Figure 4C and D) as Cul did. These results suggested that the actin cytoskeleton regulates STAT3 and STAT1 phosphorylation and that $\mathrm{CuI}$ might affect JAK/STAT signaling by disrupting the actin cytoskeleton.

STAT3 and STAT1 signaling proteins were physically associated with actin filaments

To understand how actin filaments may regulate the STATs, 
A

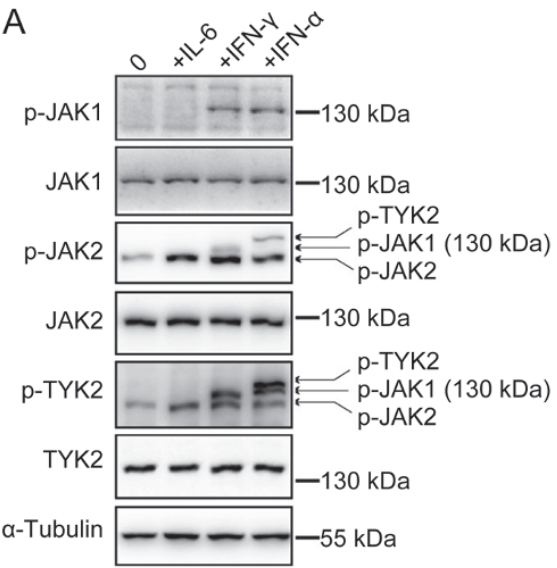

B

Cul $(\mu \mathrm{mol} / \mathrm{L}) \quad 0 \quad 0.1 \quad 0.5 \quad 1 \quad 2.5 \quad 5 \quad 10$

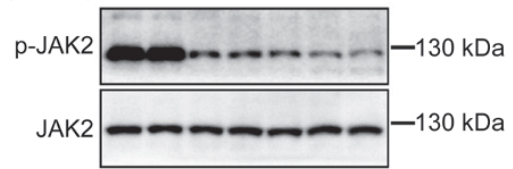

C

$\mathrm{IL}-6++++++$

Cul $(\mu \mathrm{mol} / \mathrm{L}) \quad 0 \quad 0 \quad 0.10 .5 \quad 1 \quad 5 \quad 10$

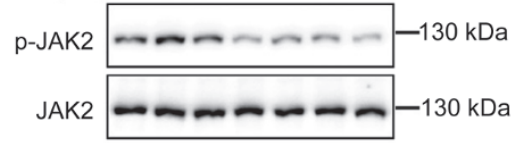

D

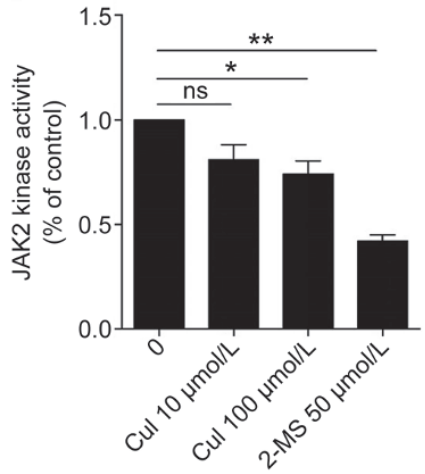

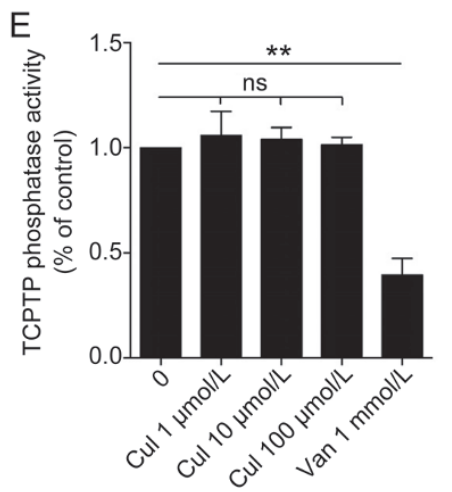

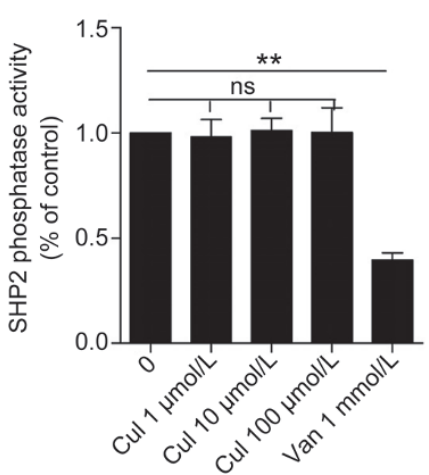

F

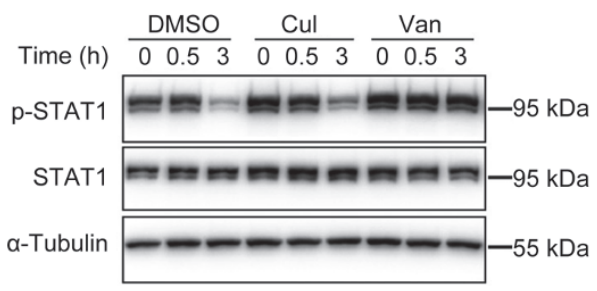

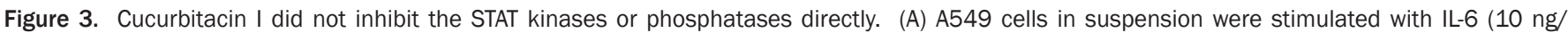

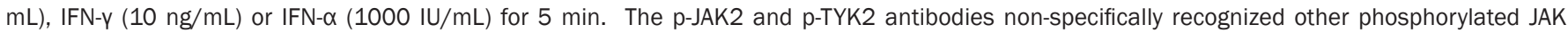

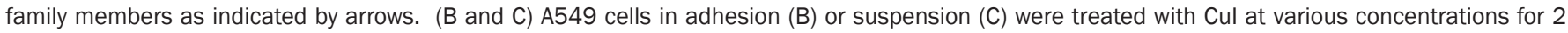

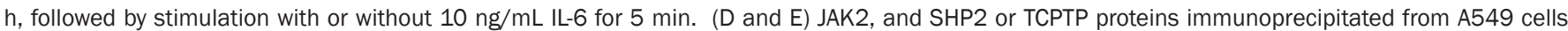

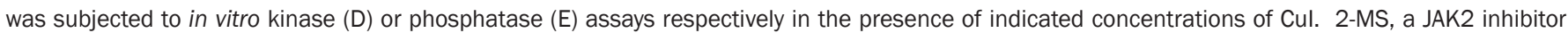

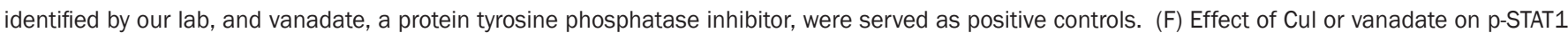

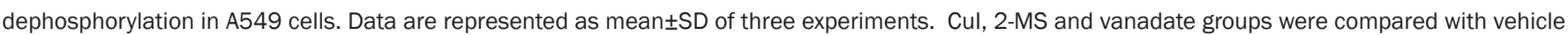
group by Student's $t$-test. ns, not significant; ${ }^{*} P<0.05 ;{ }^{* *} P<0.01$. van, vanadate.

we determined whether the actin cytoskeleton physically interacted with the signaling proteins that regulated STAT3 phosphorylation and STAT1 dephosphorylation. By pulling down actin filaments using biotinylated phalloidin, we found that the IL-6 receptors (IL-6Ra and GP130), JAK2, STAT3, STAT1, TCPTP, and SHP2 were all physically associated with actin filaments (Figure $5 \mathrm{~A}$ ), and that $\mathrm{CuI}$ or CytoD treatment disrupted the association of JAK2, GP130, and IL-6Ra with actin (Figure 5B), but not that of STAT3, STAT1, TCPTP, or SHP2 with actin (Figure 5C). Immunofluorescent staining demonstrated that GP130, JAK2/p-JAK2, and STAT3/ p-STAT3 were all colocalized with actin filaments at the cell edges (Figure 5D-G arrowheads). CuI and CytoD treatment dissociated GP130 and JAK2 from actin (Figure 5E and F). However, STAT3 and STAT1 seemed to remain associated with actin after $\mathrm{CuI}$ or CytoD treatment (Figure 5G and $\mathrm{H}$ ). These results suggested actin might regulate STAT signaling through physically interacting with STAT signaling proteins.
JAK2/STAT3 phosphorylation was regulated by two signaling complexes: the focal adhesion complex and the IL- 6 receptor complex

The immunochemical staining data suggested that some of the STAT signaling proteins might localize at focal adhesions, in addition to their membrane localization (Figure 5D). We thus examined whether p-JAK2 and p-STAT3 colocalized with vinculin, a focal adhesion maker. Immunofluorescent staining revealed that p-JAK2 and p-STAT3 indeed colocalized with vinculin in focal adhesions (Figure 6A and B). Next, we determined whether cell adhesion could regulate the phosphorylation of JAK2 and STAT3. We examined the phosphorylation of JAK2 and STAT3 during cell attachment and found that the phosphorylation of JAK2 increased upon cell attachment, but the phosphorylation of STAT3 was unaffected (Figure 6C).

To further confirm that JAK2 and STAT3 were localized at focal adhesions and were regulated by cell adhesion, we immunoprecipitated vinculin from adherent and suspended cells, respectively, and found that JAK2 and STAT3 co-immu- 
A

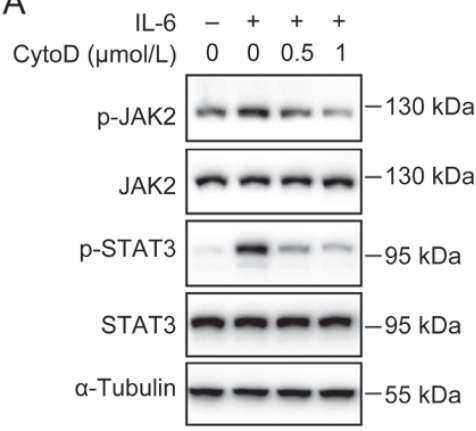

B

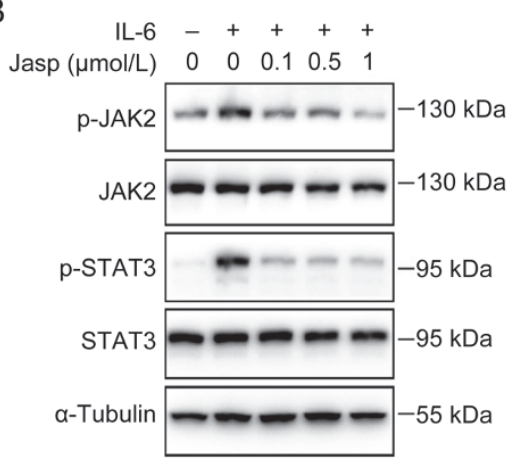

C

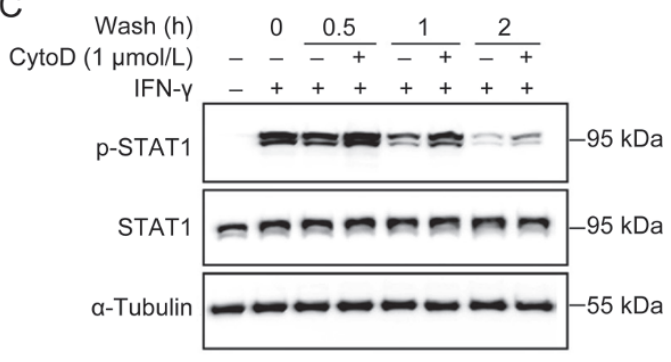

D

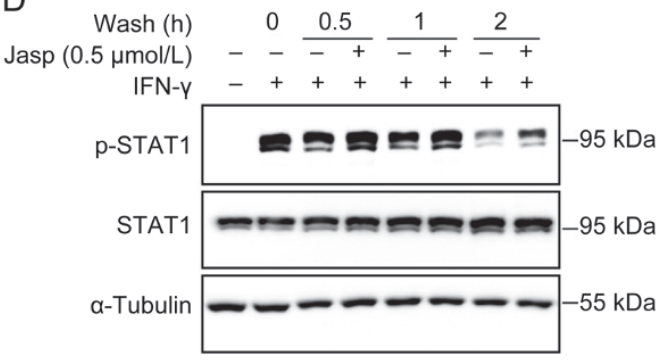

Figure 4. Disrupting actin cytoskeleton inhibited STAT3 phosphorylation and p-STAT1 dephosphorylation. (A and B) A549 cells in suspension were treated with CytoD (A) or Jasp (B) at indicated concentrations for $2 \mathrm{~h}$, followed by IL-6 (10 ng/mL) stimulation for 5 min. (C and D) Following IFN-y (10 $\mathrm{ng} / \mathrm{mL}$ ) stimulation for $30 \mathrm{~min}$, A549 cells were washed and incubated with fresh medium containing DMSO, CytoD (1 $\mu \mathrm{mol} / \mathrm{L})(\mathrm{C})$ or Jasp (0.5 $\mu \mathrm{mol} / \mathrm{L})(\mathrm{D})$ for indicated time periods.

noprecipitated with vinculin and that the phosphorylation of vinculin-associated JAK2 and STAT3 increased in adherent cells (Figure 6D). These data suggested that JAK2 and STAT3 phosphorylation could be regulated by focal adhesions.

To determine whether focal adhesion affects IL-6 receptormediated JAK2/STAT3 signaling, we treated adherent and suspended cells with IL-6 and examined the phosphorylation of JAK2 and STAT3. We found that IL-6 activated JAK2/ STAT3 signaling in both suspended and adherent cells (Figure $6 \mathrm{E})$, indicating that IL-6R/JAK2/STAT3 signaling was independent of focal adhesions. To further strengthen this conclusion, we examined whether GP130, the IL-6 signal-transducing receptor, is present in focal adhesions. We found that GP130 was not colocalized with vinculin in focal adhesions (Figure 6F). Co-immunoprecipitation experiments also excluded the possibility of the presence of either GP130 or IL-6Ra in the focal adhesions (Figure 6G). These data suggested that two signaling complexes existed that regulated JAK2/STAT3 phosphorylation, a focal adhesion complex and a cell membrane IL-6 receptor complex, both of which had interactions with actin. JAK2 and STAT3 bonded with vinculin (Figure 6H).

Cul and CytoD inhibited STAT3 phosphorylation in both signaling complexes by disrupting actin filaments

To determine whether STAT3 phosphorylation in both the focal adhesion complex and the IL-6 receptor complex was regulated by actin, we treated the cells with $\mathrm{CuI}$ and $\mathrm{CytoD}$ and examined the phosphorylation of JAK2/STAT3 in the two complexes. We noticed that stress fibers, the type of actin filaments that anchor to focal adhesions, were disrupted by $\mathrm{CuI}$ and CytoD treatment (Figure 5). No vinculin-containing focal adhesion complex existed after $\mathrm{CuI}$ and CytoD treatment, and focal adhesion-associated p-JAK2 and p-STAT3 decreased (Figure 7A and B). Co-immunoprecipitation experiments confirmed that $\mathrm{CuI}$ or CytoD decreased p-JAK2 and p-STAT3 in the vinculin/focal adhesion complex (Figure 7C). Therefore, the phosphorylation of focal adhesion-associated JAK2/ STAT3 was regulated by actin stress fibers.

We next examined whether the phosphorylation of JAK2/ STAT3 in the IL-6 receptor complex was also regulated by actin using co-immunoprecipitation experiments; we found that $\mathrm{CuI}$ and $\mathrm{CytoD}$ inhibited the IL-6-induced phosphorylation of JAK2 in the GP130 complex (Figure 7D), suggesting that IL-6 receptor-mediated JAK2/STAT3 phosphorylation was also regulated by actin.

Actin filaments regulated p-STAT1 dephosphorylation by modulating $\mathrm{p}$-STAT1 proteins, rather than by modulating the activity of protein tyrosine phosphatases (PTPs)

To understand the role and mechanisms of the actin cytoskeleton in the regulation of p-STAT1 dephosphorylation, we conducted an in vitro p-STAT1 dephosphorylation experiment in the presence or absence of actin filaments. We stimulated the cells with IFN- $\gamma$, then lysed the cells and incubated the lysates 

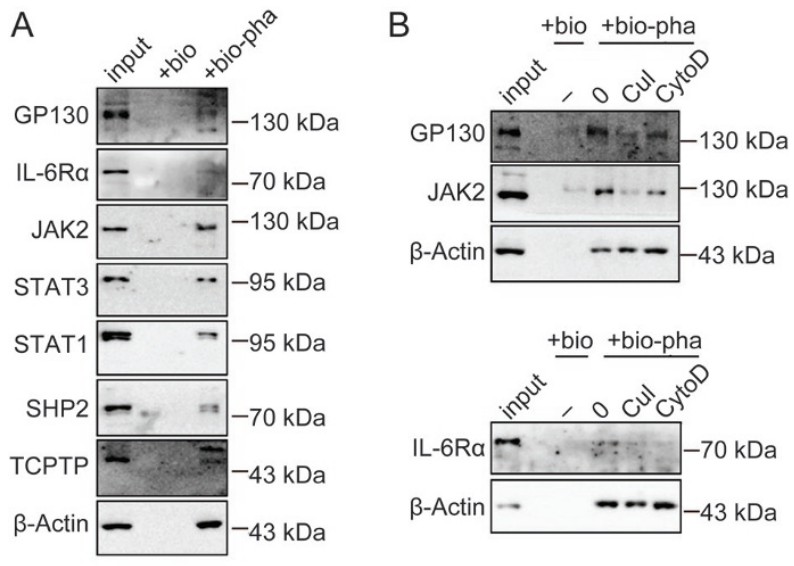

E

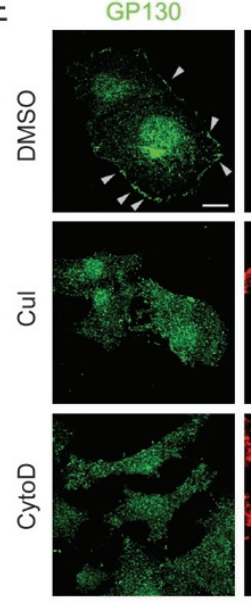

G

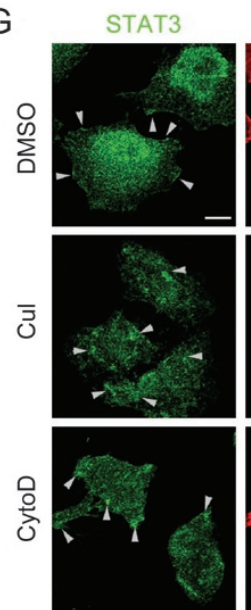

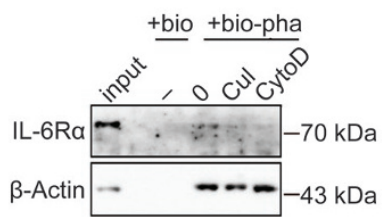

Actin
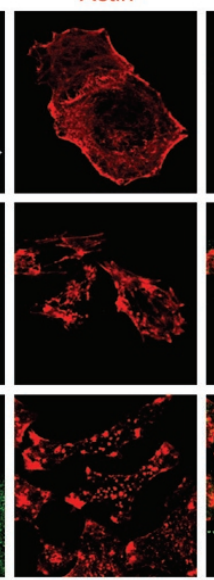

Actin
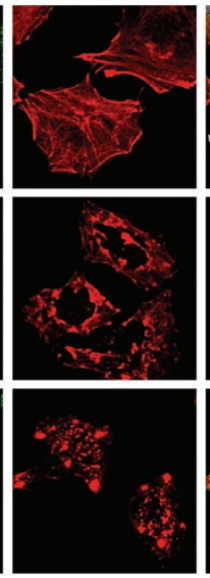

Merge

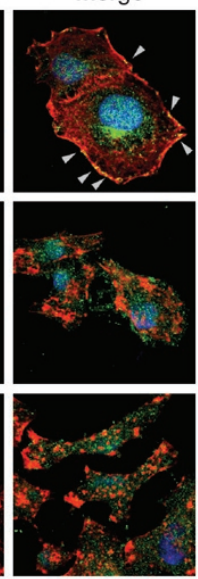

Merge

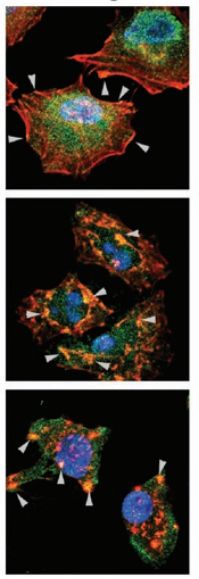

C
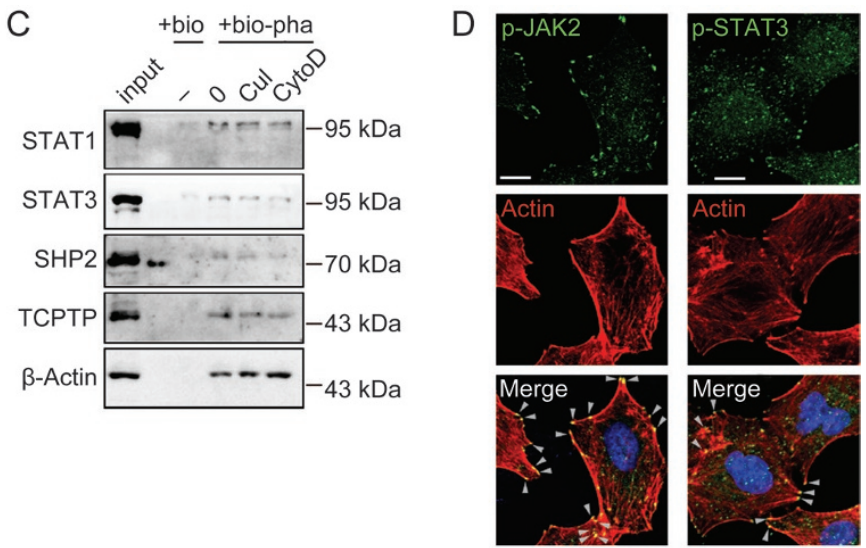

F
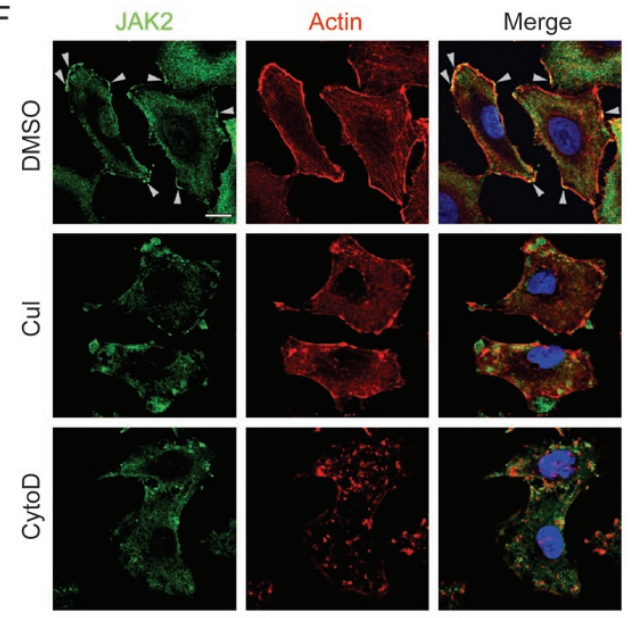

$\mathrm{H}$
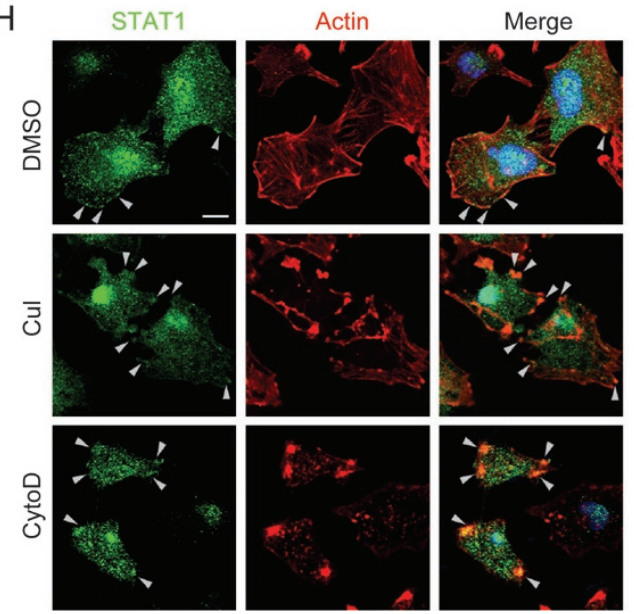

Figure 5. STAT3 and STAT1 signaling proteins were physically associated with actin filaments. (A-C) A549 cells were lysed, and actin filaments were pulled-down using biotinylated-phalloidin, followed by elution with $10 \mathrm{mmol} / \mathrm{L}$ biotin. For drug treatments in B and C, A549 cells were treated with DMSO, $0.5 \mu \mathrm{mol} / \mathrm{L}$ Cul or $1 \mu \mathrm{mol} / \mathrm{L}$ CytoD for $2 \mathrm{~h}$. input, $3 \%$ of the total cell lysates compared with $100 \%$ of the elution; bio, biotin; bio-pha, biotinylatedphalloidin. (D-H) Confocal micrographs of A549 cells staining with rhodamine-phalloidin (for actin, red), DAPI (for nucleus, blue), and antibodies against the indicated proteins (green). Arrowheads indicated colocalization of STATs signaling proteins with actin. For drug treatment, A549 cells were treated with DMSO, $0.5 \mu \mathrm{mol} / \mathrm{L} \mathrm{Cul} \mathrm{or} 1 \mu \mathrm{mol} / \mathrm{L}$ CytoD for $2 \mathrm{~h}$ prior to immunochemical staining. Scale bars, $10 \mu \mathrm{m}$.

in the absence or presence of $1 \%$ Triton X-100, which was used to precipitate actin filaments ${ }^{[57]}$. We found that p-STAT1 underwent dephosphorylation in vitro, which was inhibited by Triton X-100 (Figure 8A). To further confirm that it was the actin filaments that regulated the p-STAT1 dephosphorylation, the cell lysates were incubated with DNase I, which can bind to actin monomers and depolymerize actin filaments ${ }^{[58]}$. We found that p-STAT1 could not be dephosphorylated in the 
A
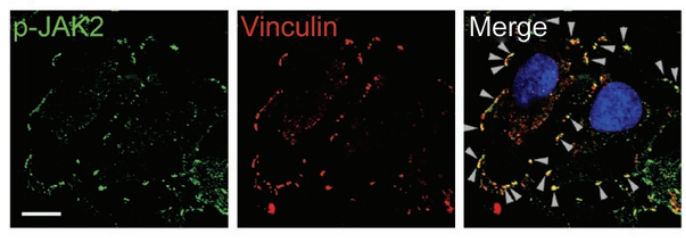

B
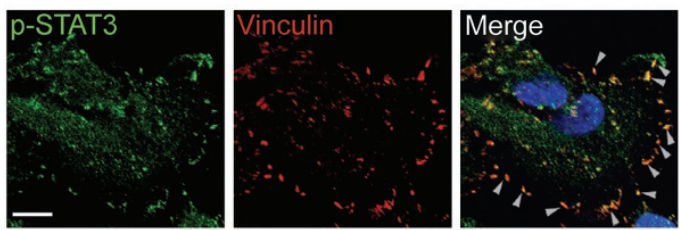

E

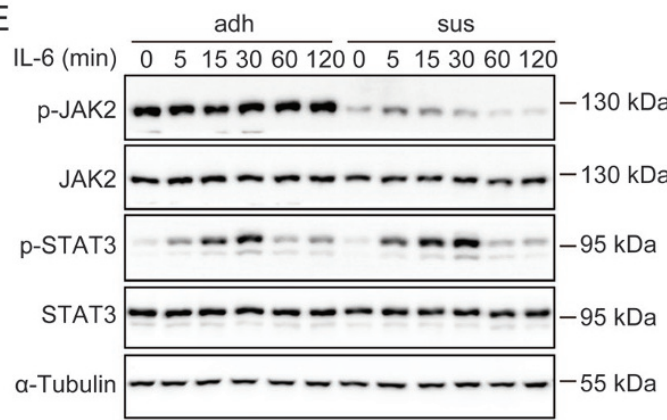

C

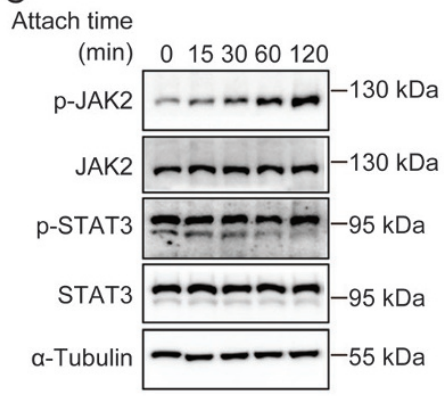

D
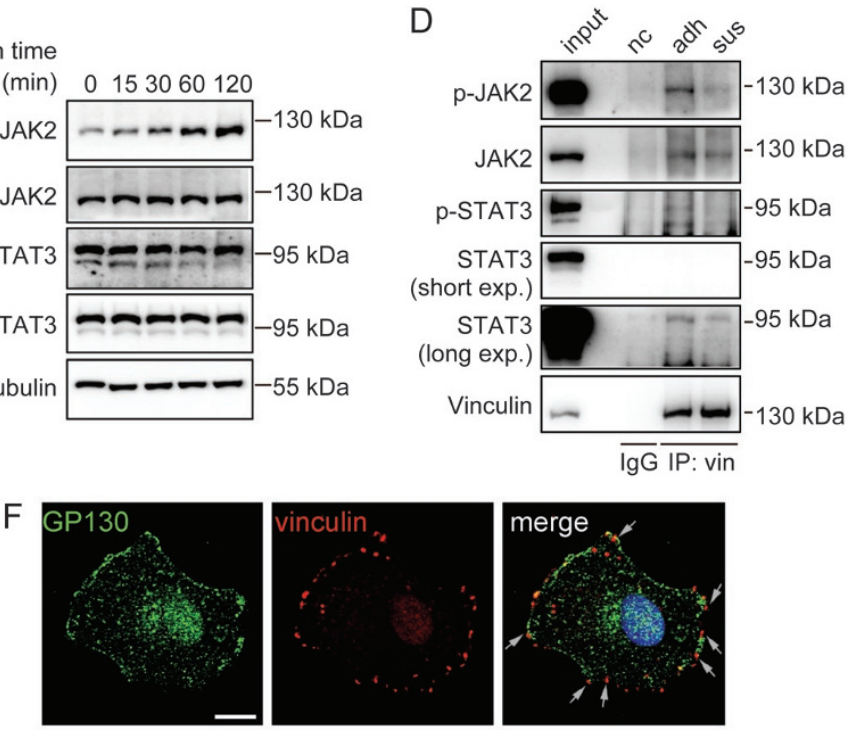

G

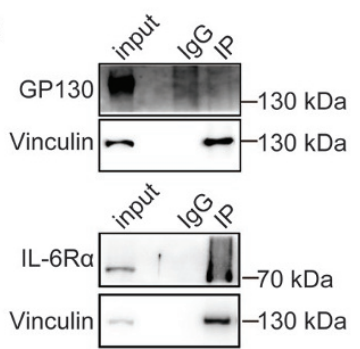

$\mathrm{H}$

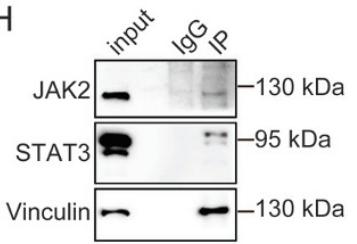

Figure 6. JAK2/STAT3 phosphorylation were regulated by two signaling complexes: the focal adhesion complex and the IL-6 receptor complex. (A and B) Confocal micrographs of A549 cell staining with DAPI (for nucleus, blue) and antibodies against vinculin (red) and p-JAK2 (green) (A) or p-STAT3 (green) (B). Arrowheads indicated the colocalization of p-JAK2 or p-STAT3 with vinculin. Scale bars, $10 \mu \mathrm{m}$. (C) A549 cells were detached by 1 mmol/L EDTA and reattached to plates for various time periods. (D) A549 cells in adhesion (adh) or suspension (sus) were immunoprecipitated for vinculin, followed by immunoblotting with indicated antibodies. (E) A549 cells in adhesion (adh) or suspension (sus) were stimulated with IL-6 (10 ng/mL) for indicated time periods. (F) Confocal micrographs of A549 cell staining with DAPI (for nucleus, blue) and antibodies against vinculin (red) and GP130 (green). Arrows indicated that GP130 and vinculin were not colocalized. Scale bar, $10 \mu \mathrm{m}$. (G and H) A549 cell lysates were immunoprecipitated for vinculin, followed by immunoblotting with indicated antibodies. Note that JAK2 and STAT3 bonded with vinculin (H) while GP130 or IL-6R $\alpha$ did not (G). input, $2.5 \%$ of the total cell lysates compared with $100 \%$ of the pellet; nc, negative control; IgG, the immunoprecipitate of IgG; IP, immunoprecipitation.

presence of DNase I (Figure 8B). These data demonstrated that filamentous actin was involved in p-STAT1 dephosphorylation.

To understand the mechanism of actin in regulating the dephosphorylation of p-STAT1, we heat-denatured the IFN$\gamma$-stimulated cell lysate and mixed it with an unstimulated cell lysate in the presence of Triton X-100. We observed that although p-STAT1 in the undenatured cell lysate could not be dephosphorylated, in the presence of Triton X-100, p-STAT1 in the heat-denatured cell lysate was dephosphorylated (Figure $8 \mathrm{C})$, demonstrating that actin was not required for p-STAT1 dephosphorylation when it was denatured. The actin filaments might regulate the conformation of p-STAT1 to expose the phosphorylated tyrosine to be dephosphorylated by phosphatases, which could also be achieved by denaturation ${ }^{[59]}$.

\section{Discussion}

Cucurbitacin I was initially identified as a potent inhibitor of cancer cell growth ${ }^{[48]}$. Investigations into its molecular mecha- nisms of action have found that actin is one of its direct targets and that the JAK2/STAT3 signaling pathway is the primary signaling pathway that is influenced by cucurbitacin $\mathrm{I}^{[48,50]}$. However, the connections between the two activities and the mechanisms of regulation of JAK2/STAT3 signaling have not yet been elucidated. Here, we present evidence demonstrating that cucurbitacin I inhibits JAK2/STAT3 phosphorylation, as well as p-STAT1 dephosphorylation, by disrupting actin filaments. The actin filaments were found to interact with distinct JAK/STAT signaling complexes located in different regions of a cell, such as the membrane cytokine receptor complexes and the focal adhesion complex, to regulate their activities. We propose that actin filaments function not only in the structure support, mobility, and contraction of cells but also as a signaling organizer and mediator to coordinate cellular signaling. By disrupting actin, cucurbitacin I, as well as other actin disruptors, altered JAK/STAT signaling and possibly caused cell cycle arrest and cell death ${ }^{[60,61]}$.

STAT1 and STAT3 are known to play opposite roles in the 
A
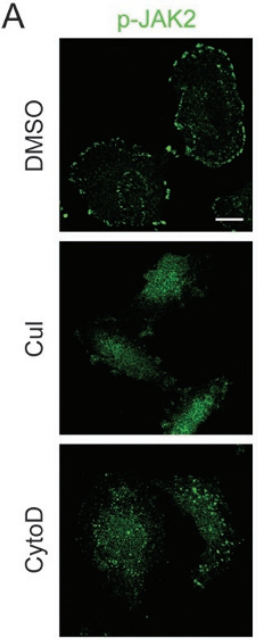

C
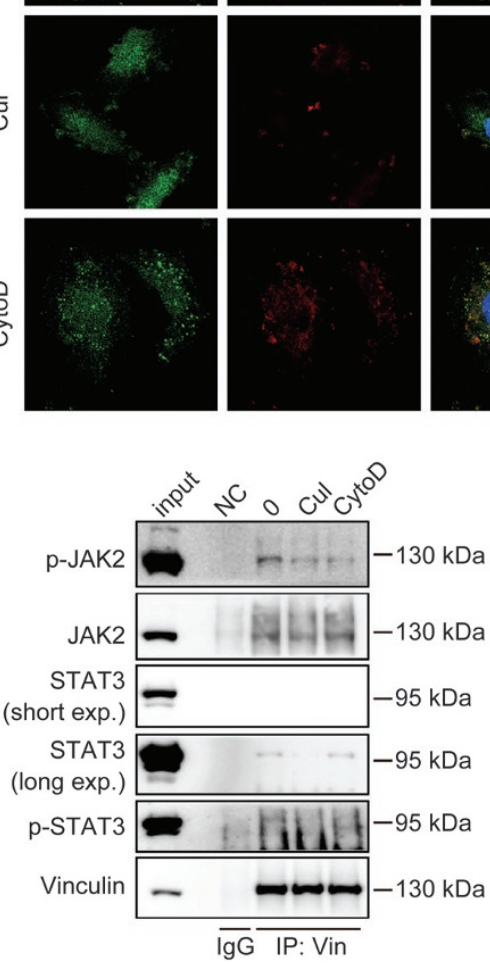

B
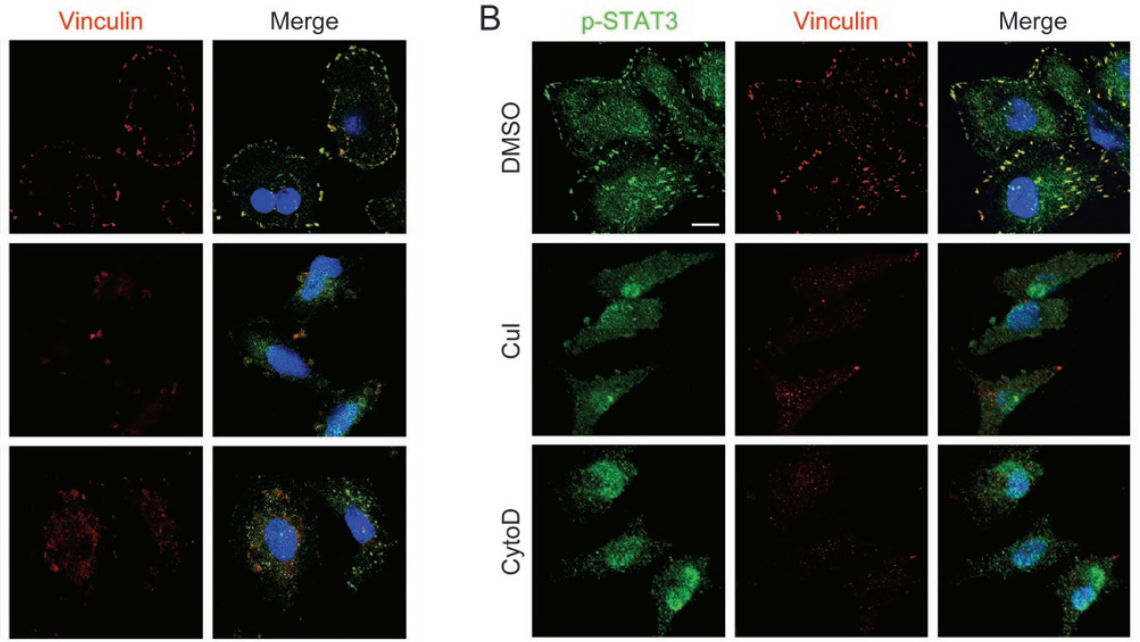

D

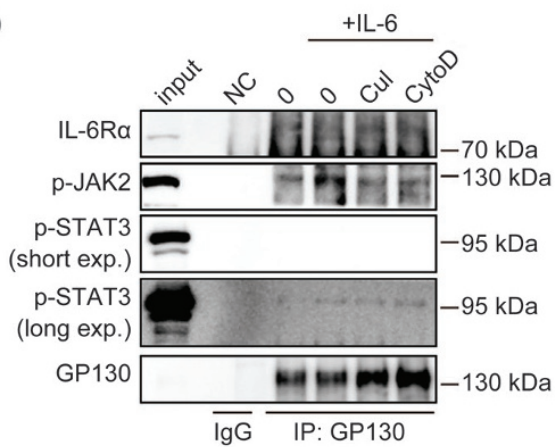

Figure 7. Cul and CytoD inhibited STAT3 phosphorylation in both signaling complexes through disrupting actin filaments. (A and B) A549 cells were treated with DMSO, Cul $(0.5 \mu \mathrm{mol} / \mathrm{L})$ or CytoD $(1 \mu \mathrm{mol} / \mathrm{L})$ for $2 \mathrm{~h}$, fixed, permeabilized, and stained with DAPI (nucleus, blue) and antibodies against vinculin and p-JAK2 (green) (A) or p-STAT3 (green) (B). Scale bars, $10 \mu \mathrm{m}$. (C) Following treatment with DMSO, Cul (0.5 $\mu \mathrm{mol} / \mathrm{L})$ or CytoD (1 $\mu \mathrm{mol} / \mathrm{L})$ for $2 \mathrm{~h}$, A549 cells were lysed and immunoprecipitated for vinculin, and the indicated proteins were detected by immunoblotting using indicated antibodies. (D) A549 cells were treated with DMSO, Cul $(0.5 \mu \mathrm{mol} / \mathrm{L})$ or CytoD $(1 \mu \mathrm{mol} / \mathrm{L})$ for $2 \mathrm{~h}$, followed by stimulation with or without IL-6 $(10 \mathrm{ng} / \mathrm{mL})$ for $5 \mathrm{~min}$, and were lysed and immunoprecipitated for GP130. The immunoprecipitates were processed for Western blot analysis. input, $2.5 \%$ of the total cell lysates compared with $100 \%$ of the pellet; nc, negative control; IgG, the immunoprecipitate of IgG; IP, immunoprecipitation.

regulation of cell growth; STAT3 transduces growth stimulatory signals and STAT1 generates growth inhibitory signals ${ }^{[2]}$. In this regard, it is interesting to note that disrupting actin filaments affected STAT1 and STAT3 phosphorylation in opposite ways, inhibiting the phosphorylation of STAT3 but the dephosphorylation of p-STAT1, and leading to decreased STAT3 activity but sustained STAT1 activity, which synergized with each other to inhibit cell growth and to induce cell death. These data again suggest that actin filaments function to coordinate different signals to control cell growth.

The primary sites for the cytokine-induced phosphorylation of STATs are in the cytokine receptor complexes at the plasma membrane. However, both STAT1 and STAT3 have also been found in focal adhesions ${ }^{[63,64]}$. Disrupting actin inhibited STAT3 phosphorylation in both the receptor signaling complexes and the focal adhesions, suggesting that actin is involved in regulating JAK2/STAT3 at both sites. The signals and mechanisms through which JAK2 and STAT3 are phos- phorylated in the focal adhesions and the mechanism through which actin regulates the phosphorylation of focal adhesionassociated JAK2 and STAT3 remain unclear. However, there is some evidence suggesting that $\beta 1$-integrin plays a role in activating focal adhesion-associated JAK2 ${ }^{[65]}$ as both JAK2 and STAT3 are physically associated with $\beta 1$-integrin (unpublished data), and actin may participate by regulating the affinity of integrin ${ }^{[66]}$. Further studies are needed to clarify these hypotheses.

Disrupting the actin filaments affected only the dephosphorylation, and not the phosphorylation, of STAT1. Phosphorylated STAT1 is translocated into the nuclei, and the dephosphorylation of p-STAT1 is believed to occur in the nuclei ${ }^{[67,68]}$; the major phosphatases involved in p-STAT1 dephosphorylation are TCPTP and SHP2 ${ }^{[5,56]}$. Our data demonstrated that actin filaments are required for the dephosphorylation of p-STAT1 both in vivo and in vitro. However, actin filaments did not affect the enzymatic activity of TCPTP or SHP2. 
A

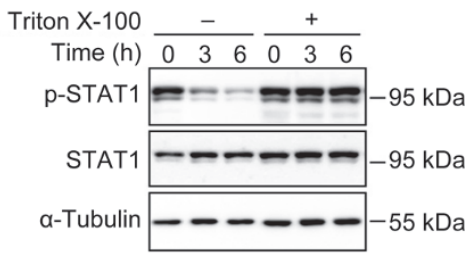

B

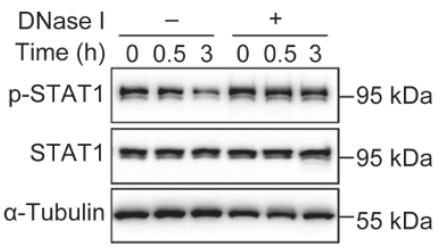

C
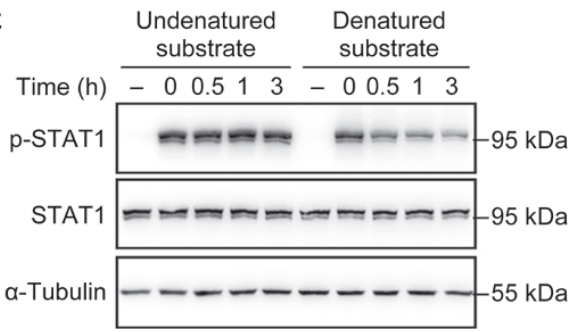

Figure 8. Actin filaments regulated p-STAT1 dephosphorylation through modulating $\mathrm{p}$-STAT1 proteins, rather than the activity of protein tyrosine phosphatases (PTPs). (A and B) A549 cells were treated with IFN-y (10 $\mathrm{ng} / \mathrm{mL}$ ) for $30 \mathrm{~min}$, and then were lysed and incubated in vitro at $36{ }^{\circ} \mathrm{C}$ in the presence or absence of $1 \%$ Triton X-100 (A) or DNase I (B) for indicated time periods. Following incubation, the lysates were mixed with laemmli $2 \times$ sample buffer and processed for Western blot analyses with indicated antibodies. (C) Two dishes of A549 cells were stimulated with or without IFN-y $(10 \mathrm{ng} / \mathrm{mL})$ respectively for $30 \mathrm{~min}$ and lysed. The IFN- $\gamma$-stimulated lysate was divided into two parts, one of which was heat-denatured while the other undenatured, and then were mixed with unstimulated cell lysates respectively and incubated at $36^{\circ} \mathrm{C}$ for indicated time periods.

Instead, they appeared to affect the conformation of p-STAT1 to make the tyrosine phosphate accessible to the phosphatase as the heat-denatured p-STAT1 could be dephosphorylated in the absence of actin filaments. Therefore, actin in nuclei may regulate the dephosphorylation of p-STAT1 by changing its conformation. Disrupting actin may send a signal through STAT1 to stop cell cycle progression to avoid inappropriate cell division.

Cucurbitacin I is a potent inhibitor of cancer cell growth and has been considered as an anti-cancer drug candidate ${ }^{[48]}$. Our data and others suggest that actin filaments may be the major target of cucurbitacin I. It is not clear what other proteins cucurbitacin I may interact with in addition to actin, but disrupting actin filaments alone may cause severe adverse effects in cancer patients. Therefore, caution should be taken when considering cucurbitacin I as a disease-treating drug.

In summary, our study has revealed the molecular mechanisms of cucurbitacin I and has uncovered a novel role of actin in the regulation of STAT1 and STAT3 signaling. Actin is essential for the phosphorylation of STAT3 and the dephosphorylation of p-STAT1 and may regulate the two signaling pathways synergistically to control cell survival and growth. Our study also suggests the existence of different JAK/STAT signaling complexes in different subcellular regions of a cell. Actin filaments may play a key role in coordinating the different signaling complexes to direct various cellular activities. These findings shed new light on understanding JAK/STAT signaling and regulation, as well as the function and mechanisms of actin.

\section{Acknowledgments}

This work was supported by the China Ministry of Science and Technology Key New Drug Creation and Manufacturing Program (№ 2014ZX9102001002 to Qiang YU), the China National Key Basic Research Program (№ 2013 CB910900 to Qiang YU), and the National Natural Science Foundation of China (№ 81373447 and 81673465 to Qiang YU).

\section{Author contribution}

Hui GUO conducted all experiments, analyzed the results, and wrote most of the paper. Shan KUANG screened cucurbitacin I. Qiao-ling SONG, Man LIU and Xiao-xiao SUN provided advice regarding the experiments. Qiang YU conceived the idea for the project and wrote the paper with Hui GUO.

\section{References}

1 Flaherty MS, Salis P, Evans CJ, Ekas LA, Marouf A, Zavadil J, et al. Chinmo is a functional effector of the JAK/STAT pathway that regulates eye development, tumor formation, and stem cell self-renewal in Drosophila. Dev Cell 2010; 18: 556-68.

2 O'Shea JJ, Plenge R. JAK and STAT signaling molecules in immunoregulation and immune-mediated disease. Immunity 2012; 36: 542-50.

3 Ward AC, Touw I, Yoshimura A. The Jak-Stat pathway in normal and perturbed hematopoiesis. Blood 2000; 95: 19-29.

4 Vainchenker W, Constantinescu SN. JAK/STAT signaling in hematological malignancies. Oncogene 2013; 32: 2601-13.

5 Thomas SJ, Snowden JA, Zeidler MP, Danson SJ. The role of JAK/ STAT signalling in the pathogenesis, prognosis and treatment of solid tumours. Br J Cancer 2015; 113: 365-71.

6 James C, Ugo V, Le Couedic JP, Staerk J, Delhommeau F, Lacout C, et al. A unique clonal JAK2 mutation leading to constitutive signalling causes polycythaemia vera. Nature 2005; 434: 1144-8.

7 Lacronique V, Boureux A, Monni R, Dumon S, Mauchauffe M, Mayeux P, et al. Transforming properties of chimeric TEL-JAK proteins in $\mathrm{Ba} / \mathrm{F} 3$ cells. Blood 2000; 95: 2076-83.

8 Koskela HL, Eldfors S, Ellonen P, van Adrichem AJ, Kuusanmaki $\mathrm{H}$, Andersson El, et al. Somatic STAT3 mutations in large granular lymphocytic leukemia. N Engl J Med 2012; 366: 1905-13.

9 Peck AR, Witkiewicz AK, Liu C, Stringer GA, Klimowicz AC, Pequignot $\mathrm{E}$, et al. Loss of nuclear localized and tyrosine phosphorylated Stat5 in breast cancer predicts poor clinical outcome and increased risk of antiestrogen therapy failure. J Clin Oncol 2011; 29: 2448-58.

10 Macha MA, Matta A, Kaur J, Chauhan SS, Thakar A, Shukla NK, et al. Prognostic significance of nuclear pSTAT3 in oral cancer. Head Neck 2011; 33: 482-9.

11 Sonnenblick A, Uziely B, Nechushtan H, Kadouri L, Galun E, Axelrod $\mathrm{JH}$, et al. Tumor STAT3 tyrosine phosphorylation status, as a predictor of benefit from adjuvant chemotherapy for breast cancer. Breast Cancer Res Treat 2013; 138: 407-13. 
12 Mirtti T, Leiby BE, Abdulghani J, Aaltonen E, Pavela M, Mamtani A, et al. Nuclear Stat5a/b predicts early recurrence and prostate cancerspecific death in patients treated by radical prostatectomy. Hum Pathol 2013; 44: 310-9.

$13 \mathrm{Xu} \mathrm{YH}$, Lu S. A meta-analysis of STAT3 and phospho-STAT3 expression and survival of patients with non-small-cell lung cancer. Eur J Surg Oncol 2014; 40: 311-7.

14 Bromberg JF, Wrzeszczynska MH, Devgan G, Zhao Y, Pestell RG, Albanese C, et al. Stat3 as an oncogene. Cell 1999; 98: 295-303.

$15 \mathrm{Yu} \mathrm{H}$, Jove R. The STATs of cancer-new molecular targets come of age. Nat Rev Cancer 2004; 4: 97-105.

16 Niu G, Wright KL, Huang M, Song L, Haura E, Turkson J, et al. Constitutive Stat3 activity up-regulates VEGF expression and tumor angiogenesis. Oncogene 2002; 21: 2000-8.

17 Cheng GZ, Zhang WZ, Sun M, Wang Q, Coppola D, Mansour M, et al. Twist is transcriptionally induced by activation of STAT3 and mediates STAT3 oncogenic function. J Biol Chem 2008; 283: 14665-73.

18 Xie TX, Wei D, Liu M, Gao AC, Ali-Osman F, Sawaya R, et al. Stat3 activation regulates the expression of matrix metalloproteinase-2 and tumor invasion and metastasis. Oncogene 2004; 23: 3550-60.

19 Yu H, Lee H, Herrmann A, Buettner R, Jove R. Revisiting STAT3 signalling in cancer: new and unexpected biological functions. Nat Rev Cancer 2014; 14: 736-46.

20 Guschin D, Rogers N, Briscoe J, Witthuhn B, Watling D, Horn F, et al. A major role for the protein tyrosine kinase JAK1 in the JAK/STAT signal transduction pathway in response to interleukin-6. EMBO J 1995; 14: 1421-9.

21 Narazaki M, Witthuhn BA, Yoshida K, Silvennoinen O, Yasukawa K, Ihle JN, et al. Activation of JAK2 kinase mediated by the interleukin 6 signal transducer gp130. Proc Natl Acad Sci U S A 1994; 91: 2285-9.

22 Dorff TB, Goldman B, Pinski JK, Mack PC, Lara PN Jr, Van Veldhuizen PJ Jr, et al. Clinical and correlative results of SWOG S0354: a phase II trial of CNTO328 (siltuximab), a monoclonal antibody against interleukin-6, in chemotherapy-pretreated patients with castrationresistant prostate cancer. Clin Cancer Res 2010; 16: 3028-34.

23 Raven JF, Williams V, Wang S, Tremblay ML, Muller WJ, Durbin JE, et al. Stat1 is a suppressor of ErbB2/Neu-mediated cellular transformation and mouse mammary gland tumor formation. Cell Cycle 2011; 10 : 794-804.

24 Dimco G, Knight RA, Latchman DS, Stephanou A. STAT1 interacts directly with cyclin D1/Cdk4 and mediates cell cycle arrest. Cell Cycle 2010; 9: 4638-49.

25 Penafuerte C, Bautista-Lopez N, Bouchentouf M, Birman E, Forner K, Galipeau J. Novel TGF-beta antagonist inhibits tumor growth and angiogenesis by inducing IL-2 receptor-driven STAT1 activation. J Immunol 2011; 186: 6933-44.

26 Kachroo P, Lee MH, Zhang L, Baratelli F, Lee G, Srivastava MK, et al. IL-27 inhibits epithelial-mesenchymal transition and angiogenic factor production in a STAT1-dominant pathway in human non-small cell lung cancer. J Exp Clin Cancer Res 2013; 32: 97.

27 Zhang Y, Zhang Y, Yun H, Lai R, Su M. Correlation of STAT1 with apoptosis and cell-cycle markers in esophageal squamous cell carcinoma. PLoS One 2014; 9: e113928.

28 Blouin CM, Hamon Y, Gonnord P, Boularan C, Kagan J, Viaris de Lesegno C, et al. Glycosylation-dependent IFN-gamma partitioning in lipid and actin nanodomains is critical for JAK activation. Cell 2016; 166: 920-34.

29 Koromilas AE, SexI V. The tumor suppressor function of STAT1 in breast cancer. JAKSTAT 2013; 2: e23353.

30 Kaplan DH, Shankaran V, Dighe AS, Stockert E, Aguet M, Old L, et al. Demonstration of an interferon gamma-dependent tumor surveillance system in immunocompetent mice. Proc Natl Acad Sci U S A 1998; 95: 7556-61.

31 Simpson JA, Al-Attar A, Watson NF, Scholefield JH, llyas M, Durrant LG. Intratumoral T cell infiltration, MHC class I and STAT1 as biomarkers of good prognosis in colorectal cancer. Gut 2010; 59: 926-33.

32 Chen G, Wang H, Xie S, Ma J, Wang G. STAT1 negatively regulates hepatocellular carcinoma cell proliferation. Oncol Rep 2013; 29: 2303-10.

33 Zhang Y, Molavi O, Su M, Lai R. The clinical and biological significance of STAT1 in esophageal squamous cell carcinoma. BMC Cancer 2014; 14: 791.

34 Sun Y, Yang S, Sun N, Chen J. Differential expression of STAT1 and p21 proteins predicts pancreatic cancer progression and prognosis. Pancreas 2014; 43: 619-23.

35 Osborn JL, Greer SF. Metastatic melanoma cells evade immune detection by silencing STAT1. Int J Mol Sci 2015; 16: 4343-61.

36 Bohmer FD, Friedrich K. Protein tyrosine phosphatases as wardens of STAT signaling. JAKSTAT 2014; 3: e28087.

37 Tojkander S, Gateva G, Lappalainen P. Actin stress fibers-assembly, dynamics and biological roles. J Cell Sci 2012; 125: 1855-64.

38 Naumanen P, Lappalainen P, Hotulainen P. Mechanisms of actin stress fibre assembly. J Microsc 2008; 231: 446-54.

39 Vicente-Manzanares M, Choi CK, Horwitz AR. Integrins in cell migration-the actin connection. J Cell Sci 2009; 122: 199-206.

40 Salbreux G, Charras G, Paluch E. Actin cortex mechanics and cellular morphogenesis. Trends Cell Biol 2012; 22: 536-45.

41 Tang J, Gross DJ. Regulated EGF receptor binding to F-actin modulates receptor phosphorylation. Biochem Biophys Res Commun 2003; 312: 930-6.

42 Samarakoon R, Higgins PJ. MEK/ERK pathway mediates cell-shapedependent plasminogen activator inhibitor type 1 gene expression upon drug-induced disruption of the microfilament and microtubule networks. J Cell Sci 2002; 115: 3093-103.

43 Are AF, Galkin VE, Pospelova TV, Pinaev GP. The p65/RelA subunit of NF-kappaB interacts with actin-containing structures. Exp Cell Res 2000; 256: 533-44.

44 Mattila PK, Batista FD, Treanor B. Dynamics of the actin cytoskeleton mediates receptor cross talk: an emerging concept in tuning receptor signaling. J Cell Biol 2016; 212: 267-80.

45 Dudnakova T, Spraggon L, Slight J, Hastie N. Actin: a novel interaction partner of WT1 influencing its cell dynamic properties. Oncogene 2010; 29: 1085-92.

46 Treanor B, Depoil D, Gonzalez-Granja A, Barral P, Weber M, Dushek 0 , et al. The membrane skeleton controls diffusion dynamics and signaling through the B cell receptor. Immunity 2010; 32: 187-99.

47 Pillet AH, Lavergne V, Pasquier V, Gesbert F, Theze J, Rose T. IL-2 induces conformational changes in its preassembled receptor core, which then migrates in lipid raft and binds to the cytoskeleton meshwork. J Mol Biol 2010; 403: 671-92.

48 Blaskovich MA, Sun J, Cantor A, Turkson J, Jove R, Sebti SM. Discovery of JSI-124 (cucurbitacin I), a selective Janus kinase/signal transducer and activator of transcription 3 signaling pathway inhibitor with potent antitumor activity against human and murine cancer cells in mice. Cancer Res 2003; 63: 1270-9.

49 Zhang Y, Ouyang D, Xu L, Ji Y, Zha Q, Cai J, et al. Cucurbitacin B induces rapid depletion of the $\mathrm{G}$-actin pool through reactive oxygen species-dependent actin aggregation in melanoma cells. Acta Biochim Biophys Sin (Shanghai) 2011; 43: 556-67.

50 Sorensen PM, lacob RE, Fritzsche M, Engen JR, Brieher WM, Charras G, et al. The natural product cucurbitacin $E$ inhibits depolymerization of actin filaments. ACS Chem Biol 2012; 7: 1502-8. 
51 Nakashima S, Matsuda H, Kurume A, Oda Y, Nakamura S, Yamashita $\mathrm{M}$, et al. Cucurbitacin $\mathrm{E}$ as a new inhibitor of cofilin phosphorylation in human leukemia U937 cells. Bioorg Med Chem Lett 2010; 20 : 2994-7.

52 Sun X, Ai M, Wang Y, Shen S, Gu Y, Jin Y, et al. Selective induction of tumor cell apoptosis by a novel P450-mediated reactive oxygen species (ROS) inducer methyl 3-(4-nitrophenyl) propiolate. J Biol Chem 2013; 288: 8826-37.

53 Fulga TA, Elson-Schwab I, Khurana V, Steinhilb ML, Spires TL, Hyman $\mathrm{BT}$, et al. Abnormal bundling and accumulation of F-actin mediates tau-induced neuronal degeneration in vivo. Nat Cell Biol 2007; 9: 139-48.

54 Mitzel DN, Jaramillo RJ, Stout-Delgado H, Senft AP, Harrod KS. Human metapneumovirus inhibits the IL-6-induced JAK/STAT3 signalling cascade in airway epithelium. J Gen Virol 2014; 95: 26-37.

55 Wu TR, Hong YK, Wang XD, Ling MY, Dragoi AM, Chung AS, et al. SHP-2 is a dual-specificity phosphatase involved in Stat1 dephosphorylation at both tyrosine and serine residues in nuclei. J Biol Chem 2002; 277: 47572-80.

56 ten Hoeve J, de Jesus Ibarra-Sanchez M, Fu Y, Zhu W, Tremblay M, David $\mathrm{M}$, et al. Identification of a nuclear Stat1 protein tyrosine phosphatase. Mol Cell Biol 2002; 22: 5662-8.

57 Ujfalusi-Pozsonyi K, Hild G, Grof P, Gutay-Toth Z, Bacso Z, Nyitrai M. The effects of detergents on the polymerization properties of actin. Cytometry A 2010; 77: 447-56.

58 Hitchcock SE, Carisson L, Lindberg U. Depolymerization of F-actin by deoxyribonuclease I. Cell 1976; 7: 531-42.

59 Mertens C, Zhong M, Krishnaraj R, Zou W, Chen X, Darnell JE Jr. Dephosphorylation of phosphotyrosine on STAT1 dimers requires extensive spatial reorientation of the monomers facilitated by the
N-terminal domain. Genes Dev 2006; 20: 3372-81.

60 Premkumar DR, Jane EP, Pollack IF. Cucurbitacin-I inhibits Aurora kinase A, Aurora kinase B and survivin, induces defects in cell cycle progression and promotes ABT-737-induced cell death in a caspaseindependent manner in malignant human glioma cells. Cancer Biol Ther 2015; 16: 233-43.

61 Tong ZG, Liu N, Song HS, Li JQ, Jiang J, Zhu JY, et al. Cytochalasin $B$ inhibits the proliferation of human glioma U251 cells through cell cycle arrest and apoptosis. Genet Mol Res 2014; 13: 10811-22.

62 Avalle L, Pensa S, Regis G, Novelli F, Poli V. STAT1 and STAT3 in tumorigenesis: A matter of balance. JAKSTAT 2012; 1: 65-72.

63 Silver DL, Naora H, Liu J, Cheng W, Montell DJ. Activated signal transducer and activator of transcription (STAT) 3: localization in focal adhesions and function in ovarian cancer cell motility. Cancer Res 2004; 64: 3550-8.

64 Xie B, Zhao J, Kitagawa M, Durbin J, Madri JA, Guan JL, et al. Focal adhesion kinase activates Stat1 in integrin-mediated cell migration and adhesion. J Biol Chem 2001; 276: 19512-23.

65 Balanis N, Wendt MK, Schiemann BJ, Wang Z, Schiemann WP, Carlin CR. Epithelial to mesenchymal transition promotes breast cancer progression via a fibronectin-dependent STAT3 signaling pathway. J Biol Chem 2013; 288: 17954-67.

66 Bennett JS, Zigmond S, Vilaire G, Cunningham ME, Bednar B. The platelet cytoskeleton regulates the affinity of the integrin alpha(Ilb) beta(3) for fibrinogen. J Biol Chem 1999; 274: 25301-7.

67 Meyer T, Marg A, Lemke P, Wiesner B, Vinkemeier U. DNA binding controls inactivation and nuclear accumulation of the transcription factor Stat1. Genes Dev 2003; 17: 1992-2005.

68 Reich NC, Liu L. Tracking STAT nuclear traffic. Nat Rev Immunol 2006; 6: 602-12. 